\title{
RESPONSABILIDADE CIVIL DOS MÉDICOS NO EXERCÍCIO DA TELEMEDICINA
}

\author{
CIVIL RESPONSIBILITY OF PHYSICIANS IN THE EXERCISE OF \\ TELEMEDICINE
}

\author{
Ana Luiza Machado Vilas Boas ${ }^{1}$ \\ Priscila Elise Alves Vasconcelos ${ }^{2}$
}

\begin{abstract}
RESUMO: Em meio a pandemia provocada pelo Covid-ı, tornou-se relevante o distanciamento social e por consequência o uso de recursos de telemedicina no atendimento médico. Contudo, a resolução que regulamenta este atendimento é extremamente desatualizada e anterior ao advento das ferramentas que viabilizam sua aplicação de forma eficaz. Posto isso este trabalho procura aprofundar os estudos já existentes quanto ao uso da telemedicina no Brasil e a responsabilização atribuída aos médicos nesta modalidade de atendimento, através da realização de uma comparação entre as legislações vigentes no Brasil e em outros países, bemcomo o levantamento das tecnologias disponíveis e os impactos desta modalidade de atendimento. A pesquisa desenvolvida terá natureza exploratória e consistirá em pesquisa bibliográfica em artigos científicos, doutrinas, jurisprudências e legislações que façam referência a regulamentação da telemedicina no Brasil e em outras nações. E por fim, o projetotraz a hipótese da telemedicina ter caminhado para se tornar uma prática definitiva e regulamentada no futuro da medicina pós-pandemia no Brasil.
\end{abstract}

Palavras-chave: Telemedicina. Responsabilidade civil. Pandemia.

ABSTRACT: In the midst of the pandemic caused by Covid-ig, social distancing has become relevant, and consequently the use of telemedicine resources in medical care. However, the resolution that regulates this service is extremely outdated and prior to the advent of tools that enable its effective application. Therefore, this work seeks to deepen existing studies regarding the use of telemedicine in Brazil and the accountability attributed to physicians in this type of care, through a comparison between the current legislation in Brazil and in other countries, as well as a survey of available technologies and the impacts of this type of care. The research developed will be exploratory in nature and will consist of bibliographic research in scientific articles, doctrine, jurisprudence and legislation that make reference to the regulation of telemedicine in Brazil and in other nations. And finally, the project brings the hypothesis that telemedicine is on its way to becoming a definitive and regulated practice in the future of post-pandemic medicine in Brazil.

Keywords: Telemedicine. Civil liability. Pandemic.

\footnotetext{
I Discente do curso de Direito da Universidade Federal da Grande Dourados - UFGD. E-mail: Analuiza.mvbr6ı_@gmail.com.

2 Docente do curso de Direito da Universidade Federal da Grande Dourados - UFGD. Estágio Pós-doutoral em Direito das Cidades- (UERJ). Doutora em Direito-(UVA RJ). Pesquisadora GGINNS área Direito Ambiental Econômico. Professora universitária. E-mail: priscilavasconcelos@ufgd.edu.br
} 


\section{INTRODUÇÃO}

"A cura está ligada ao tempo e às vezes também às circunstâncias"”, estas palavras que foram proferidas na antiga Grécia, pelo médico Hipócrates, já demonstravam a importância daadaptabilidade das práticas médicas diante novas situações.

Por conseguinte, é importante reconhecer que o Brasil é um país de dimensões continentais, com precárias redes de transporte terreste e um grande número de pequenas comunidades isoladas (mais de mais de $65 \%$ dos municípios brasileiros têm menos de 20.00o habitantes) que sofrem com a desigualdade numérica e qualitativa na distribuição de recursos humanos e materiais na saúde pública ${ }^{4}$.

Com efeito, a telemedicina aparece nesse cenário como meio de minimizar a dificuldadede acesso, pois torna possível o atendimento sem a necessidade do profissional da saúde e o paciente estarem fisicamente no mesmo local.

Neste contexto, é perceptível que o estado de emergência acarretado pelo surgimento daPandemia do Covid-ı modificou a forma pela qual a medicina costumava ser praticada no Brasil. Com a teleconsulta passando a ser considerada regra e a consulta presencial a exceção, tornou-se necessário o desenvolvimento de normas que regulamentassem a atuação dos profissionais da saúde no exercício da telemedicina.

Por esta razão, este trabalho visa aprofundar os estudos referentes a responsabilidade civil dos médicos no exercício da telemedicina, de modo a buscar possíveis razões que expliquem porque o uso da telemedicina é visto com tantas ressalvas no Brasil, enquanto esta tem sido em outros países, uma prática já amplamente utilizada nos anos que antecederam a Pandemia.

Em vista disso, este artigo será dividido em três partes, a primeira abordará o contexto histórico do surgimento da telemedicina no Brasil e no mundo, bem como a legislação existente nos Estados Unidos e alguns dos países europeus; em um segundo momento discorreremos a respeito da responsabilidade civil dos médicos brasileiros no uso da telemedicina; e por último,serão debatidos os benefícios/vantagens versus os obstáculos/

${ }^{3}$ PENSADOR. Hipócrates. 2021. Disponível em: https://www.pensador.com/frase/Nzk4MA/>. Acesso em 20ago. 2021.

${ }^{4}$ SABBATINI, Renato M. E. A Telemedicina no Brasil: Evolução e Perspectivas. São Bernardo do Campo:Yendis, 19 Disponível em:〈https://www.sabbatini.com/renato/papers/Telemedicina_Brasil_Evolucao_Perspectivas.pdf $>$. Acesso em Io abr. 202I. 
desvantagens desta prática.

Já a metodologia empregada terá natureza exploratória e consistirá em um estudo de pesquisa bibliográfica e documental. As principais fontes utilizadas serão artigos científicos, doutrinas e legislações que façam referência a regulamentação da telemedicina no Brasil e emoutras nações. Ademais, a abordagem empregada possuirá natureza teórica e qualitativa, em virtude da utilização de análises obtidas através da percepção e interpretação dasespecificidades do assunto.

Além disso, serão suscitadas questões relativas a responsabilização civil dos médicos, ao discorrer a respeito da possibilidade das prestações de serviço via telemedicina seguirem ospadrões normativos e éticos usuais do atendimento presencial.

Por fim, tenta-se compreender como a pandemia mudou a forma que a telemedicina é vista e aplicada no país, além de tentar presumir quais serão as novidades legislativas inspiradasna experiência trazida pelo período emergencial.

\section{DA ORIGEM DA TELEMEDICINA}

\subsection{Breves considerações sobre a evolução histórica da telemedicina}

Existem diversas versões a respeito do surgimento da telemedicina. Uma das primeiras versões relatadas e mais difundidas diz que esta modalidade foi praticada pela primeira vez no continente europeu durante a Idade Média. Em razão das pragas que devastavam a Europa na época.

As histórias a respeito deste evento narram que com a propagação da contaminação, umdos médicos teria decidido se isolar, indo para a margem oposta do rio onde a população se banhava e, à distância, se comunicava com um ajudante comunitário para que este fosse capaz de auxiliar a população. Ou seja, o ajudante transmitia informações sobre os sintomas e a progressão da doença e o médico lhe passava as orientações a serem seguidas.

Contudo, esta história não pode ser comprovada, já que a primeira utilização da qual temos registro no mundo científico ocorreu em I9Io com a invenção do estetoscópio eletrônicopor S.G.Brown em Londres. A divulgação desta nova tecnologia ocorreu através do artigo "A Telephone Relay" publicado no Journal of the Institution of Electrical Engineers, e foi recebidacom muito receio pela classe médica da época. 
Posteriormente, em meados do século XIX, com o advento do rádio, telégrafo e da telegrafia o atendimento médico remoto passou a ser praticado, sendo utilizado inclusive na Primeira e Segunda Guerra Mundial. Ademais, no início do século XX, por volta de I910, já

era possível a transmissão telefônica de eletrocardiogramas (ECG), eletroencefalogramas (EEG) e sons amplificados de auscultas por estetoscópios.

Além disso, nos anos 6o, com o advento da "corrida espacial", a NASA se dedicou emdesenvolver novas tecnologias de telecomunicação que auxiliassem no monitoramento das funções vitais de seus astronautas durante missões espaciais ${ }^{6}$.

Nas décadas seguintes, surgiram inúmeros projetos pioneiros, na tentativa de aplicar as tecnologias emergentes na prestação de cuidados de saúde à distância. Um exemplo disso ocorreu nos Estados Unidos, em 1964, onde foi utilizado um circuito fechado de televisão para que os médicos do Instituto de Pesquisa de Nebraska e do Hospital Psiquiátrico Estadual de Norfolk realizassem, via vídeo, consultas interativas entre si, há uma distância de aproximadamente I8o quilômetros ${ }^{7}$.

Já na Europa, a iniciativa de transmitir dados referentes a diagnósticos surgiu na década de 7o, em decorrência de uma iniciativa da Groelândia em obter conexão com a Dinamarca para o recebimento de serviços de saúde. Tal medida foi especialmente útil quando se considerao grande problema de locomoção causado pelo inverno rigoroso destes países ${ }^{8}$.

A maior dificuldade na implementação e popularização da telemedicina durante todo século passado foi a inexistência de redes digitais de ampla cobertura, o que passou a existir a partir dos anos 90. Propiciando assim, o desenvolvimento acelerado das comunicações digitais,o qual, aliado a diminuição de custos na produção e distribuição têm

\footnotetext{
${ }^{5}$ VIANA, Fernanda Martins. Telemedicina: uma ferramenta para ampliar o acesso à assistência em saúde no Brasil. FGV EARSP, 2015, p. 22. Disponível em: 〈https://eaesp.fgv.br/producao-intelectual/telemedicina- ferramenta-para-ampliaracesso-assistencia-saude-brasil>. Acesso em I2 abr. 2021.

${ }^{6}$ FALEIROS JUNIOR, José Luiz de Moura; NOGAROLI, Rafaella; CAVET, Caroline Amadori. Telemedicina e Proteção de Dados: Reflexões sobre a pandemia da Covid-ı́ e os impactos jurídicos da tecnologia aplicada à saúde. São Paulo: Revista dos Tribunais, 2020, p. 03.

${ }^{7}$ VIANA, Fernanda Martins. op. cit., p. 23.

8 MORSCH, José Aldair. COMO FUNCIONA A TELESSAÚdE NO BRASIL, SUA LEGISLAÇÃO E BENEFÍCIOS. Telemedicina $\quad$ Morsch, 2020. Disponível em: 〈https://telemedicinamorsch.com.br/blog/telessaude-brasil〉. Acesso em Io abr. 2021.
} 
desencadeado um expressivo aumento no uso da Telemedicina.

Por fim, cumpre mencionar a adoção da "Declaração de Tel Aviv" pela $5 I^{\mathbf{a}}$ Assembléia Geral da Associação Médica Mundial, em Israel, no ano de 1999. Tornando-a um instrumento de referência mundial no que se refere as "responsabilidades e normas éticas na utilização da telemedicina"9.

\subsection{Telemedicina nos Estados Unidos}

De acordo com a American Telemedicine Association (ATA), o campo relativamente novo da telemedicina cresceu e se tornou uma indústria multibilionária nos últimos anos. Segundo dados do Department of Health and Human Services, em fevereiro de 2020, um mês antes da Declaração de Emergência de Saúde Pública nos Estados Unidos em decorrência da Covid-ı9, a tele saúde foi responsável por apenas o,oooı\% das visitas de atenção primária do Medicare. No entanto, apenas dois meses depois, cerca de metade destas visitas passaram aser realizadas de forma virtual ${ }^{10}$.

Além disso, segundo dados da "Global Med" cerca de 74\% dos millennials (pessoas que nasceram de 1980 a 2000) preferem visitas de telessaúde a exames médicos presenciais ${ }^{\text {II }}$. Issotudo indica que esta modalidade tem sido considerada uma alternativa bem-vinda em relação as demoradas e caras visitas aos consultórios médicos nos Estados Unidos.

Já em fevereiro de 2016, introduziu-se pela primeira vez o projeto de lei “Connect for Health Act", que foi considerado até recentemente, a legislação mais abrangente sobre teles saúde presente no Congresso dos Estados Unidos. Este projeto visava remover várias restrições no uso da telemedicina, como por exemplo: a limitação por localização geográfica; regras estritas sobre as tecnologias de armazenamento e envio; restrições em relação a inclusão de tratamentos psiquiátricos, cuidados com AVC, diálise domiciliar e etc.

\footnotetext{
${ }^{9}$ DHNET. Declaração de Telavive sobre responsabilidades e normas éticas na utilização da telemedicina. Adotada pela $5 \mathrm{I}^{\mathrm{a}}$ Assembléia Geral da Associação Médica Mundial em Tel Aviv, em outubro de 1999. Disponível em: $\langle$ http://www.dhnet.org.br/direitos/codetica/medica/27telaviv.html〉. Acesso em 20 abr. 202I.

10 SHAH, Bimal. The Pandemic Changed Telehealth; Next, Telehealth May Change Healthcare. Amererican Telemed, 2021.Disponível em: <https://www.americantelemed.org/blog/teladochealth6-II/>. Acesso em I2 abr. 202I.

${ }^{\text {II }}$ Telemedicina não para de avançar nos Estados Unidos;

Disponível em: https://brasiltelemedicina.com.br/artigo/telemedicina-avanca-estados-unidos/
} 
Por conseguinte, desde 20ı6, várias disposições do projeto de lei foram promulgadas ou adotadas pelos Centros de Serviços Medicare e Medicaid. Em seguimento a este progresso, em 2021, foi apresentada uma versão atualizada do "Connect for Health Act", a qual incluiu e revisou antigas disposições a fim de melhorar e expandir o acesso aos serviços de telessaúde de forma permanente.

Com as disposições presentes no projeto pretende-se:

1) Remover permanentemente todas as restrições geográficas aos serviços de telessaúde, permitindo que o benificiário seja atendido onde quer que esteja.

2) Permitir que centros de saúde e clínicas rurais de saúde forneçam serviços de telessaúde, uma disposição atualmente em vigor devido à pandemia, mas em caráter temporário;

3)Fornecer ao Secretário de Saúde e Serviços Humanos autoridade permanente para dispensar as restrições de telessaúde, uma disposição atualmente em vigor devido à pandemia, mas em caráter temporário;

4)Permitir a dispensa de restrições de telessaúde durante emergências de saúdepública

5)Exigir um estudo para saber mais sobre como a telessaúde foi usada durante a atualpandemia COVID-19. ${ }^{\text {I2 }}$

Nos Estados Unidos, este projeto foi apoiado por mais de 150 organizações não governamentais defensoras de direitos relacionados à saúde e à telessaúde ${ }^{\mathrm{I3}}$, as quais reconheceram a crescente melhora na infraestrutura dos sites e aplicativos que forneceram atendimento médico ao longo da pandemia do Covid-ı.

Em decorrência disto, pode-se dizer que a pandemia nos deu um vislumbre do futuro das relações entre médico e paciente, fazendo com que os legisladores norte americanos demonstrassem maior interesse em aprovar uma nova regulamentação sobre a utilização da telemedicina, uma vez que esta se tornou reconhecidamente capaz em fornecer serviços de altaqualidade de maneira segura e eficaz.

\footnotetext{
${ }^{12}$ ATA NEWS. Schatz, Wicker Lead Bipartisan Group Of so Senators In Reintroducing Legislation To Expand Telehealth Access, Make Permanent Telehealth Flexibilities Available During COVID-ı9Pandemic. American Tele Med, 202I. Disponível em: 〈https://www.americantelemed.org/policy/schatz-wicker-lead-bipartisan-group-of-so-senatorsin-reintroducing-legislation-to-expand-telehealth-access-make-permanent- telehealth-flexibilities-available-during-covidI9-pandemic/>. Acesso em I2 abr. 2021.

${ }^{13}$ BERTOLINI, Gina L. Connect for Health Act of 2021 Reintroduced. 2021. Disponível em: $\langle$ https://www.natlawreview.com/article/connect-health-act-2021-reintroduced $>$. Acesso em I2. Abr. 202I.
} 


\subsection{Telemedicina na Europa}

Uma pesquisa conduzida pela Healthcare Information and Management Systems Society - HIMSS, publicada na revista INSIGHTS, no verão de 2020, amealhou informações a respeito da utilização da telemedicina por países europeus antes do início pandemia.

De acordo com os cinco especialistas consultados para a elaboração do artigo supramencionado, já existia na Europa, antes da disseminação do Covid-ı,, a infraestrutura necessária para que a telessaúde fosse amplamente utilizada em diversos países europeus. No entanto, esta costumava ser raramente utilizada em razão da existência de uma barreira cultural:tanto os médicos quanto os pacientes preferiam ter interações face a face.

É importante ressaltar ainda que as modalidades de uso e a regulamentação da telemedicina variam significativamente de um país para o outro no continente europeu ${ }^{\mathrm{I}}$ :

\section{What type of telehealth solutions or telehealth related services do you already provide?}

Only health, facilities, technology vendors and consuting companies that provide telehealth. Total also includes "others": Multiple choices:

Values for countries / fegions weighted according to the datribution of "type of argarization" in the sample.
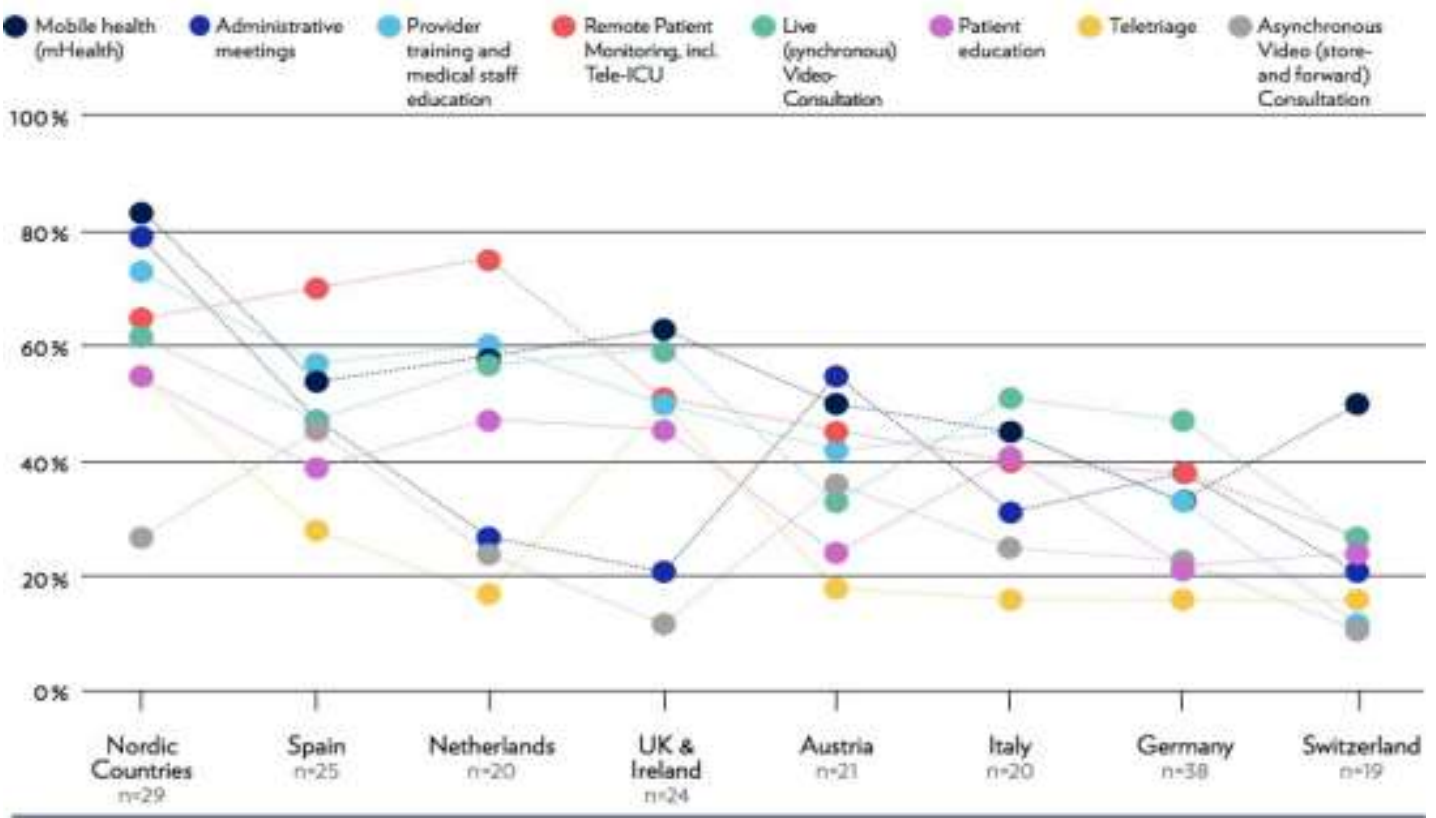

Fonte: Saúde Business, 2020.

${ }^{14}$ SAÚDE BUSINESS. O cenário europeu da telessaúde. AGRJ, Socgastro, 2020. Disponível em: <https://socgastro.org.br/novo/2020/o7/o-cenario-europeu-da-telessaude/>. Acesso em I2 abr. 2021. 
Conforme a pesquisa, os países nórdicos seguem na liderança no que diz respeito a implementação das mais diversas modalidades de telemedicina na Europa. Enquanto isso, a Alemanha e a Suíça apresentam resultados mais conservadores na adoção desta modalidade dentre os países analisados.

A Dinamarca, um dos países nórdicos com a mais elevada taxa de adoção de telessaúde, tem vindo a utilizá-la como instrumento para manter os pacientes que não precisam ser atendidos presencialmente longe dos hospitais e consultórios dinamarqueses. Desta forma, tornou-se possível atender um maior número de pessoas sem a necessidade de grandes gastos com insumos, infraestrutura e pessoal. Tal estratégia permitiu ainda que o "número de leitos para cada I.ooo pessoas fosse reduzido de 8,5 em 1975 para apenas 2,5 em 2015" sem impactarnegativamente no acesso à saúde da população.

Outro país a implementar a telessáude em seu cotidiano com sucesso é a França, que jávêm elaborando leis que autorizam o atendimento médico a distância desde 2009. As primeiras leis postas em vigor no país objetivavam definir o que é telemedicina (Article L.6316-I du Code

de la santé publique) ${ }^{15}$ e descrever suas modalidades (Article R63ı-I créé par Décret $n^{\circ}$ 2010-II29 du 19 octobre 2010$)^{16}$.

Posteriormente, em 2018, foram realizadas negociações entre o seguro de saúde e os sindicatos dos médicos para definir os termos e condições do pagamento dos atos de teleconsulta. Este acordo determinou que os atos praticados por teleconsulta a partir do dia 15/09/2018 fossem reembolsados ${ }^{17}$ da mesma maneira que as consultas convencionais, encorajando assim a generalização desta prática por todo território francês.

Já em Portugal, o interesse na telemedicina remonta a 1999, ano em que foi criada a Comissão de Acompanhamento da Iniciativa Estratégica para o Desenvolvimento da Telemedicina (CIEDT). Contudo, embora tenha havido este entusiasmo inicial, foi somente a partir da emissão da Portaria n.o 567/2006 que o Serviço Nacional de Saúde

\footnotetext{
is LEGIFRANCE. Article L6316-I. Modifilé par LOI no 2017-1836 du 30 décembre 2017 - art. 54 (V). Disponível em:<https://www.telemedecine-36o.com/wp-content/uploads/2019/or/D\%C3\%A9finition-

t\% $\mathrm{C}_{3 \%} \mathrm{~A}_{9} 1 \% \mathrm{C}_{3 \%} \mathrm{~A}_{9}$ m\% $\mathrm{C}_{3 \%}$ A9decine.pdf $>$. Acesso em 12 abr. 202I.

${ }^{16}$ Idem.

${ }^{17}$ ROUZIC, Mathilde le. Remboursement des teléconsultations. Hellocare, blog, 202r. Disponível em:

〈https://blog.hellocare.pro/remboursement-des-teleconsultations〉. Acesso em I2 abr. 2021.
} 
regulamentou pela primeira vez os valores a serem cobrados pela prestação de serviços médicos de forma virtual:

Artigo 15.ํ: Consulta externa

1 - O valor a facturar pelas consultas é o seguinte:

a) Instituições que integram o Serviço Nacional de Saúde, bem como as que a este estejam associadas através de contrato de gestão e ainda o Instituto Português do Sangue e o Serviço de Prevenção e Tratamento da Toxicodependência:

Consultas médicas - (euro) 30 ;

b) Hospitais psiquiátricos, departamentos, serviços ou unidades de psiquiatria os constantes da tabela de psiquiatria do anexo III.

2 - As consultas médicas sem a presença do utente e as consultas de telemedicina serão facturadas ao valor das consultas médicas.

3 - As teleconsultas poderão ser facturadas por ambas as instituições envolvidas desdeque cumpram os requisitos definidos em normativo da Direcção-Geral da Saúde. ${ }^{18}$

O Despacho n. ${ }^{-0} 3571 / 2013^{19}$ emitido pelo gabinete do Secretário de Estado Adjunto do Ministro da Saúde é atualmente o principal documento normativo dedicado a telemedicina em Portugal. Dentre suas disposições, o despacho chegou a indicar quais seriam as especialidades médicas tidas como prioritárias (dermatologia, cardiologia, cardiologia pediátrica, neurologia, fisiatria e pneumologia) e estabeleceu que as teleconsultas deveriam ocorrer, sempre que possível, de forma síncrona.

além disso, o mesmo despacho estabeleceu, em concordância com o disposto no artigo94, $\mathrm{n}^{\circ} 2$ do CDOM que o médico só deve recorrer à telemedicina quando tiver "uma ideia clara e justificável da situação clínica do paciente”, ou seja, é aconselhável que o primeiro contato entre médico e paciente seja feito de forma presencial.

Desta forma, é perceptível que muito país europeu já vem se esforçando a anos para incorporar esta nova modalidade de atendimento no cotidiano de seus cidadãos. Isso se deve principalmente ao fato de que a telemedicina torna possível a:

[...] prestação de serviços médicos a pacientes que não têm condições, quer econoômicas, quer geográficas, ou até mesmo de saúde, para se deslocarem aos consultórios médicos e aos hospitais. A barreira da distância é, assim, ultrapassada, permitindo ao paciente uma poupança nos custos de deslocação e um

\footnotetext{
${ }^{18}$ BRASIL. Portaria n.o 567/2006. Diário da República Eletrônico, Ministério da Saúde, p. 4173-4267, 2006. Disponível em: 〈https://dre.pt/pesquisa/-/search/346716/details/maximized〉. Acesso em 29 set. 2021.

${ }^{19}$ DIÁRIOS DA REPÚBLICA. Despacho 3571/2013, de 6 de Março. Ministério da Sáude - Gabinete do Secretário de Estado Adjunto do Ministério da Saúde, o6-03-2013. Disponível em:

〈https://dre.tretas.org/dre/30746I/despacho-3571-2013-de-6-de-marco〉. Acesso em o7 mar. 2021.
} 
tratamento maisrápido. ${ }^{20}$

\subsection{Telemedicina no Brasil}

No Brasil, o primeiro uso da telemedicina do qual se tem registro ocorreu em 1987, durante o episódio em que centenas de pessoas foram expostas direta ou indiretamente ao césio radioativo encontrado em um aparelho de radioterapia abandonado na cidade de Goiânia. Apósesta exposição, algumas das vítimas foram internadas em Goiânia e outras tiveram que ser transferidas para outros hospitais em Brasília, Rio de Janeiro e Campinas. Em razão da distância, a fim de trocar informações diárias sobre a evolução do quadro das vítimas, "uma equipe médica da Unicamp, responsável pela emissão dos laudos do acidente, utilizou-se da rede de comunicação do Núcleo de Informática Biomédica da Faculdade de Ciências Médicas (FCM) da UNICAMP”, para entrar em contato com os médicos dos demais hospitais.

Posteriormente, em 1995, o Instituto do Coração (INCOR) criou a Telecardiologia, para analisar eletrocardiogramas efetuados em outras localidades. Já no ano seguinte, este mesmo instituto introduziu uma iniciativa que permitiria o telemonitoramento dos pacientes em seus próprios domicílios.

Outro marco importante para telemedicina brasileira ocorreu no ano de 2000, momentono qual o Instituto Materno Infantil de Recife realizou as primeiras teleconsultas com patologistas e radiologistas de um hospital estrangeiro (Saint Jude Children Research Hospital) localizado em Memphis, nos Estados Unidos. No mesmo ano em São Paulo, o Hospital Sírio Libanês em parceria com o hospital norte americano John Hopkins realizou a primeiratelecirurgia empregando um robô e um computador portátil, vale ressaltar ainda que este procedimento foi transmitido ao vivo para o $18^{\circ}$ Congresso Mundial de EndoUrologia ${ }^{22}$.

${ }^{20}$ DUARTE, Andreia Filipa Santos. TELEMEDICINA: OS NOVOS DESAFIOS À RESPONSABILIDADE CIVIL MÉDICA: a emergência de uma nova forma de prestar consentimento. Dissertação (Mestrado) - Curso deDireito, 6of, Universidade do Porto, Porto, 2018. Disponível em: <https://repositorioaberto.up.pt/bitstream/ı0216/117905/2/304384.pdf >. Acesso em I2 abr. 2021.

FALEIROS JUNIOR, José Luiz de Moura; NOGAROLI, Rafaella; CAVET, Caroline Amadori. Telemedicina eProteção de Dados: Reflexões sobre a pandemia da Covid-rg e os impactos jurídicos da tecnologia aplicada à saúde. São Paulo: Revista dos Tribunais, 2020.

${ }^{21}$ VIANA, Fernanda Martins. op. cit., p. 27.

${ }^{22}$ SANTOS, Weverson Soares; SOUZA JÚNIOR, João Henrique; SOARES, João Coelho; RAACH, Michele. REFLEXÕES ACERCA DO USO DA TELEMEDICINA NO BRASIL: OPORTUNIDADE OU AMEAÇA?. Revista 
Além disso, é importante mencionar que o ministério da saúde em um esforço conjuntocom as secretarias estaduais e municipais deram origem ao "Programa Telessaúde Brasil Redes" com o objetivo de fortalecer a atenção primária, reduzir custos, transpor barreiras geográficas, socioeconômicas e culturais através da teleducação, teleconsultorias e telediagnósticos.

Vale apontar ainda que uma das iniciativas do "Programa de Telessaúde Brasil Redes”, denominada "Rede Universitária de Telemedicina” - RUTE é considerada uma das maiores referências em telemedicina na saúde pública brasileira, em virtude da promoção de mais de 600 reuniões por ano através da utilização de videoconferências para compartilhar experiências, resultados e efetuar pesquisas colaborativas entre médicos brasileiros e estrangeiros.

\subsubsection{Primeiras decisões legislativas sobre o uso da telemedicina no Brasil}

No que concerne a legislação e regulamentação, a telemedicina foi instituída no país por meio da Resolução CFM n ${ }^{\circ}$ I.643/2002, do Conselho Federal de Medicina. Uma das maiores contribuições trazidas por esta resolução foi sem dúvida a apresentação de uma definição para a telemedicina no Brasil “[...] o exercício da Medicina através da utilização de metodologias interativas de comunicação audio-visual e de dados, com o objetivo de assistência, educação epesquisa em Saúde” ${ }^{23}$.

vale ressaltar que este documento normativo não foi muito abrangente, pois deixou deprever a regulamentação de várias modalidades presentes na Declaração de Tel Aviv ${ }^{24}$, tais como a teleconsulta, telediagnóstico, telecirurgia, teleconferência de ato cirúrgico, teletriagem, telemonitoramento, teleorientação e teleconsultoria. No entanto, apesar de suas limitações este instrumento regulatório também estabeleceu uma exceção em seu

de Gestão em Sistemas de Saúde - RGSS, Health Systems Management Journal - HSMJ, 23. Jun. 2020, e-ISSN: $2316-3712$. Disponível em: 〈https://periodicos.uninove.br/revistargss/article/view/r7514〉. Acesso em Ioabr. 202I.

${ }^{23}$ CONSELHO REGIONAL DE MEDICINA DO ESTADO DE SÃO PAULO. Resolução CFM no ı.643, de 7 de Agosto de 2002. Conselho Federal de Medicina, Diário Oficial da União, Poder Executivo, Brasília, DF, 2002.Disponí em: $\left\langle\right.$ https://www.cremesp.org.br/?siteAcao $=$ PesquisaLegislacao\& $\mathrm{dif}=\mathrm{s} \&$ ficha $=\mathrm{I} \& \mathrm{id}=3106 \&$ tipo $=\mathrm{RESOLU} \% \mathrm{C}_{7} \%$

$\mathrm{C}_{3} \mathrm{O}$ \&orgao $=$ Conselho\%20Federal\%20de\%20Medicina\&numero $=1643 \&$ situacao $=$ VIGENTE\&data $=07-08-2002>$. Acesso I5 mai. 2021.

${ }^{24}$ DHNET. Declaração de Telavive sobre responsabilidades e normas éticas na utilização da telemedicina. Adotada pela 51 ${ }^{\mathrm{a}}$ Assembléia Geral da Associação Médica Mundial em Tel Aviv, em outubro de 1999. Disponível em: 〈http://www.dhnet.org.br/direitos/codetica/medica/27telaviv.html〉. Acesso em 20 abr. 202I. 
artigo $3^{\circ}$, ao determinar que "Em caso de emergência, ou quando solicitado pelo médico responsável, o médico que emitir o laudo à distância poderá prestar suporte diagnóstico e terapêutico"25.

Posteriormente, uma resolução mais completa foi publicada em 13 de dezembro de 2018 (Resolução CFM n ${ }^{\circ} 2.227 / 18$ ), mas acabou sendo revogada pela Resolução CFM n ${ }^{\circ} 2.228 / 19^{26}$ antes mesmo de entrar em vigor. O novo instrumento regulatório visava a ampliação da definição da telemedicina e cobria diversas lacunas deixadas pela Resolução nº I.643/2002. Desta forma, a fim de elucidar as diferenças presentes entre ambas resoluções extraí a tabela abaixo do artigo "Reflexões acerca do uso da telemedicina no Brasil: oportunidade ou ameaça?" ${ }^{27}$.

Tabela I - Comparativo Resolução I.643/o2 versus Resolução 2.227/18

\begin{tabular}{|c|c|}
\hline Resolução I.643/o2 & Resolução 2.227/18 \\
\hline $\begin{array}{c}\text { Definia a telemedicina } \\
\text { como o exercício da } \\
\text { medicina através da } \\
\text { utilização de metodologias } \\
\text { interativasde comunicação } \\
\text { audiovisual e de } \\
\text { dados, com o objetivo de } \\
\text { assistência,educação e } \\
\text { pesquisa em saúde. }\end{array}$ & $\begin{array}{c}\text { Definia a telemedicina como o exercício damedicina } \\
\text { mediado por tecnologias para fins de assistência, } \\
\text { educação, pesquisa, prevenção de doenças e lesões e } \\
\text { promoção de saúde. }\end{array}$ \\
\hline $\begin{array}{c}\text { Estabelecia que os serviços } \\
\text { de telemedicina deveriam } \\
\text { obedecer às normas técnicas } \\
\text { do CFM pertinentes à } \\
\text { guarda, manuseio, } \\
\text { transmissão de }\end{array}$ & $\begin{array}{c}\text { Reafirma o que dizia a resolução r.643/oz eacrescenta, } \\
\text { ainda, que os dados e imagens devem trafegar na } \\
\text { internet com infraestrutura, gerenciamento de riscos e } \\
\text { requisitos obrigatórios para assegurar oregistro digital } \\
\text { apropriado e seguro. }\end{array}$ \\
$\begin{array}{c}\text { dados, confidencialidade, } \\
\text { privacidadee garantia de } \\
\text { sigilo profissional. }\end{array}$ & \\
\hline & \\
\hline
\end{tabular}

\footnotetext{
${ }^{25}$ CONSELHO REGIONAL DE MEDICINA DO ESTADO DE SÃO PAULO. op. cit., p. I.

${ }^{26}$ ASSOCIAÇÃO BRASILEIRA DE MANTENEDORIAS DE ENSINO SUPERIOR. RESOLUÇÃO № 2.228 , DE 26 DE FEVEREIRO DE 2019. ABMES, 2019. Disponível em:<https://abmes.org.br/arquivos/legislacoes/ResolucaoCFM-2228-2018-02-26.pdf >. Acesso em I2 abr. 2021.

${ }^{27}$ SANTOS, Weverson Soares; SOUZA JÚNIOR, João Henrique; SOARES, João Coelho; RAACH, Michele.op. cit., p. I.
} 


\begin{tabular}{|c|c|}
\hline & $\begin{array}{c}\text { geográficos, porém com prévio atendimentopresencial. } \\
\text { Nos atendimentos por longo }\end{array}$ \\
\hline Não previa a teleconsulta. & $\begin{array}{l}\text { tempo ou de doenças crônicas, é recomendado consulta } \\
\text { presencial em intervalos máximos de } 120 \text { dias. A } \\
\text { relação médico- paciente apenas de modo virtual é } \\
\text { permitido para cobertura assistencial em áreas } \\
\text { geograficamente remotas. Devem ser garantidas as } \\
\text { condições de segurança dos registros médicos, devendo } \\
\text { ser encaminhada ao paciente cópia do relatório, } \\
\text { assinado pelomédico responsável pelo teleatendimento, } \\
\text { com garantia de autoria digital. Se, da teleconsulta } \\
\text { decorrer prescrição médica, esta deverá conter, } \\
\text { obrigatoriamente, identificação do médico, } \\
\text { identificação do } \\
\text { paciente, registro de data e hora e assinaturadigital do } \\
\text { médico. }\end{array}$ \\
\hline Não previa o telediagnóstico. & $\begin{array}{l}\text { Define o telediagnóstico como a transmissão } \\
\text { de gráficos, imagens e dados para emissão de laudo ou } \\
\text { parecer. }\end{array}$ \\
\hline Não previa a telecirurgia & $\begin{array}{l}\text { Telecirurgia é definida como a realização de } \\
\text { procedimento cirúrgico remoto, mediado por } \\
\text { tecnologias interativas seguras, com médico executor e } \\
\text { equipamento robótico em espaços físicos distintos, o } \\
\text { procedimento deve ser realizado em locais com } \\
\text { infraestrutura adequada e que além do cirurgião } \\
\text { remoto, um cirurgião local } \\
\text { acompanhe o procedimento para realizar, senecessário, a } \\
\text { manipulação instrumental. }\end{array}$ \\
\hline $\begin{array}{l}\text { Não previa a teleconferência } \\
\text { de atocirúrgico. }\end{array}$ & $\begin{array}{l}\text { Estabelece que a teleconferência de ato cirúrgico, por } \\
\text { videotransmissão síncrona, pode ser feita para fins de } \\
\text { ensino ou treinamento, desde que o grupo de recepção } \\
\text { de imagens, dados e áudios seja compostopor médicos. }\end{array}$ \\
\hline \multirow[t]{2}{*}{ Não previa a teletriagem } & $\begin{array}{l}\text { Estabelece que a teletriagem médica é o ato realizado à } \\
\text { distância por um médico para a avaliação dos sintomas } \\
\text { e direcionamento do } \\
\text { paciente a adequada assistência. }\end{array}$ \\
\hline & $\begin{array}{l}\text { declaração de saúde para a contratação ou } \\
\text { adesão a plano privado de assistência àsaúde. }\end{array}$ \\
\hline Não previa a teleconsultoria. & $\begin{array}{l}\text { Estabelece que a teleconsultoria é o ato de consultoria } \\
\text { mediada por tecnologias entre médicos e gestores, } \\
\text { profissionais e trabalhadores da área da saúde, com a } \\
\text { finalidade de esclarecer dúvidas sobre } \\
\text { procedimentos, ações de saúde e questões relativas ao } \\
\text { processo de trabalho. }\end{array}$ \\
\hline
\end{tabular}




\begin{tabular}{|c|c|}
\hline $\begin{array}{c}\text { Em caso de emergência, ou } \\
\text { quando solicitado pelo } \\
\text { médico responsável, o } \\
\text { médico que emitir o laudo } \\
\text { à distânciapoderá prestar } \\
\text { suporte diagnóstico e } \\
\text { terapêutico. }\end{array}$ & \multicolumn{1}{|c|}{ Redação foi mantida sem alterações. } \\
\hline $\begin{array}{c}\text { Não previa autorização do } \\
\text { pacientepara a transmissão } \\
\text { de dados. }\end{array}$ & $\begin{array}{l}\text { Estabelece que o paciente ou seu representante legal } \\
\text { deverá autorizar a transmissão das suas imagens e } \\
\text { dados pormeio de consentimento informado, livre e } \\
\text { esclarecido, por escrito e assinado, ou degravação da } \\
\text { leitura do texto. }\end{array}$ \\
\hline $\begin{array}{c}\text { Não previa o } \\
\text { telemonitoramento }\end{array}$ & $\begin{array}{l}\text { Define o telemonitoramento como o ato realizado sob } \\
\text { orientação e supervisão médica para monitoramento à } \\
\text { distância de parâmetros de saúde ou doença, por meio } \\
\text { de aquisição direta de imagens, sinais e dados de } \\
\text { equipamentos ou dispositivos agregados } \\
\text { ou } \\
\text { implantáveis no paciente. O } \\
\text { telemitoramento pode ser implementado emcom }\end{array}$ \\
\hline $\begin{array}{c}\text { Não previa a } \\
\text { teleorientação. }\end{array}$ & $\begin{array}{c}\text { A teleorientação é definida como o preenchimento à } \\
\text { distância, pelo médico, de unidades. }\end{array}$ \\
\hline
\end{tabular}

Fonte: Adaptado de CFM, 2019.

Depois de ser revogada sob o pretexto de que “(...) já chega a I.444 contribuições (...) de inúmeras entidades médicas, que pedem mais tempo para analisar o documento e enviar também suas sugestões de alteração" 28 , voltou a viger até a emissão da Portaria ${ }^{\circ}$ 467/2020 e do Ofício CFM N ${ }^{\circ}$ I.756/2020, elaborados a fim de regular a utilização de telemedicina ao longo do enfrentamento da emergência de saúde púbica ocasionada pelo Covid-ı9, a antiga Resolução n ${ }^{\circ}$ I.643/2002.

\subsubsection{A influência da pandemia na implementação da telemedicina no Brasil}

\footnotetext{
${ }^{28}$ CONSELHO FEDERAL DE MEDICINA. Conselheiros do CFM revogam a Resolução no 2.227/2018, quetrata da Telemedicina. Portal CFM, 2019. Disponível em: 〈https://portal.cfm.org.br/?option=com_content $\&$ id=28096\%3A2019-02-22-15-13-20 $>$. Acesso em 26 out. 2020.
} 

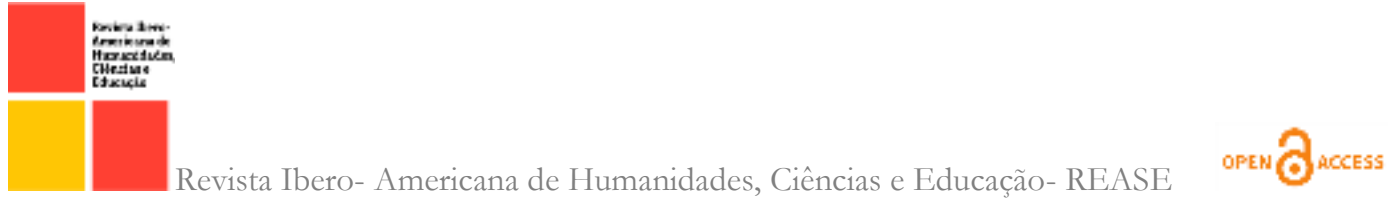

Considerando a necessidade da prestação de atendimento médico de qualidade e a importância da manutenção do distanciamento social como medida de precaução ao contágio do Covid-I9, o Conselho Federal de Medicina entendeu como prudente aprovar, mesmo que em caráter temporário e excepcional o uso da Telemedicina em todo o território nacional.

Esta foi uma das razões para que, logo no início da pandemia, em i9 de março de 2020, o Conselho Federal de Medicina reconheceu por meio do Ofício CFM I. $756 / 2020$, a

possibilidade e a eticidade da utilização da telemedicina em caráter de excepcionalidade e enquanto durar a batalha de combate ao contágio da Covid-ı.

Paralelamente a remessa do ofício do CFM ao Ministro de Estado da Saúde, entrou emvigor, no dia 20 de março de 2020, a Portaria $n^{\circ} 467 / 2020$. A qual autorizou que as ações de telemedicina realizadas à distância pudessem contemplar os tópicos a seguir: o atendimento pré-clínico, de suporte assistencial, de consulta, monitoramento e diagnóstico, por meio de tecnologia da informação e comunicação, no âmbito do SUS, bem como na saúde suplementare privada ${ }^{29}$.

Vale ressaltar que mesmo antes da vigência da Portaria de $n^{\circ} 467 / 2020$, a qual tornou lícita e ética a prática da telemedicina durante o período de pandemia, médicos e pacientes informalmente já faziam uso de conversas telefônicas, redes sociais e aplicativos de mensagens para obter informações, monitorar o bem estar dos pacientes, prescrever medicamentos e etc. Diante deste quadro, é imprescindível que a prática da telemedicina possua uma regulamentação adequada para o período pós-pandemia a fim de garantir a integridade, segurança e sigilo das informações médicas, bem como proporcionar uma maior segurança jurídica as partes (médico e paciente).

\section{DA RESPONSABILIDADE CIVIL MÉDICA}

Segundo o artigo, artigo 95ı do Código Civil Brasileiro:

Art. 951. O disposto nos arts. 948, 949 e 950 aplica-se ainda no caso de indenização

\footnotetext{
${ }^{29}$ BRASIL. PORTARIA № 467, DE 20 DE MARÇO DE 2020. Disponível em: 〈http://www.planalto.gov.br/CCIVIL_03/Portaria/PRT/Portaria\%20n\%C2\%BA\%20467-20-ms.htm> Acesso em 29 set. 2021.
} 
devida por aquele que, no exercício de atividade profissional, por negligência, imprudência ou imperícia, causar a morte do paciente, agravar-lhe o mal, causarlhe lesão, ou inabilitá-lo para o trabalho ${ }^{30}$

Assim sendo, percebe-se que o artigo em questão, refere-se, principalmente, aos profissionais da saúde como médicos, farmacêuticos e dentistas. Ressaltando que caso uma ação ou omissão praticada por eles resulte na morte, inabilidade para o trabalho, ou ferimento, caracterizar-se-á a existência da culpa. E, portanto, o dever de indenizar o paciente ou seus familiares afetados pelo erro médico causado por sua negligência, imprudência ou imperícia.

\section{1 natureza jurídica da relação médico-paciente}

A natureza jurídica da relação médico-paciente é um tema comumente analisado pela maior parte dos doutrinadores que discorrem a respeito do instituto jurídico da responsabilidade civil, mais especificamente, por aqueles cujo o enfoque é a responsabilidade médica.

Nesse sentido, percebemos que o embate jurídico entre estes especialistas gira em torno da caracterização desta relação como: contratual ou extracontratual. Como perceberemos a seguir, a grande maioria possui a opinião de que, o vínculo entre médico e paciente será sempre negocial, repelindo-se, portanto, a falsa concepção de que possa se tratar de uma responsabilidade civil em sentido estrito.

\subsubsection{O contrato de prestação de serviços médicos}

De proêmio, cabe destacar o conceito de profissional liberal para que, mais tarde, seja explicada como a responsabilidade civil destes profissionais esta associada a prestação de serviços médicos via telemedicina.

De acordo com o artigo $\mathrm{I}^{\circ}, \$^{\circ}{ }^{\circ}$, do Estatuto Social da Confederação Nacional dos Profissionais Liberais (CNPL), o profissional liberal é

[...] aquele legalmente habilitado a prestação de serviços de natureza técnicocientífica de cunho profissional com a liberdade de execução que lhe é assegurada pelos princípios normativos de sua profissão, independentemente de vínculo da

\footnotetext{
${ }^{30}$ BRASIL. LEI № 10.406, DE 10 DE JANEIRO DE 2002. Código Civil. Disponível em:

〈http://www.planalto.gov.br/ccivil_03/leis/2002/lio406.htm\#art948>. Acesso em 4 out. 2021.
} 
prestação de serviço. ${ }^{3 \mathrm{I}}$

Sobre isto, o jurista brasileiro Sergio Cavalieri Filho afirma que:

Profissional liberal, como o próprio nome indica, é aquele que exerce uma profissão livremente, com autonomia, sem subordinação. Em outras palavras, presta serviços pessoalmente, por conta própria, independente do grau de escolaridade. Não só o médico, o advogado, o engenheiro, o psicólogo, o dentista, etc. podem ser profissionais liberais, mas também o sapateiro, o carpinteiro, o marceneiro, o eletricista, o pintor, a costureira, desde que prestam serviços com autonomia, sem subordinação - enfim, por conta própria.

Neste contexto, vale ressaltar ainda que o fato destes profissionais serem liberais, não os impede de responder pelos danos causados como consequência dos seus serviços. A distinção na responsabilização destes profissionais reside no fato de não ser objetiva, exigindo,portanto, que a parte prejudicada comprove a existência de culpa.

Além disso, é necessário registrar que toda relação envolvendo um consumidor e um profissional liberal é classificada como relação de consumo. Desta forma, é válido afirmar queo médico enquanto profissional liberal, também está sujeito ao artigo ${ }^{4}, \$ 4^{\circ}$ do Código de Defesa do Consumidor (CDC):

\footnotetext{
Art. 14. O fornecedor de serviços responde, independentemente da existência de culpa, pela reparação dos danos causados aos consumidores por defeitos relativos à prestação dos serviços, bem como por informações insuficientes ou inadequadas sobresua fruição e riscos. $[\ldots]$

$\S 4^{\circ} \mathrm{A}$ responsabilidade pessoal dos profissionais liberais será apurada mediante a verificação de culpa. ${ }^{32}$
}

Ao analisar o artigo supramencionado percebemos que o código não confere aos médicos um regimento especial ou privilegiado, ele apenas se limita a mencionar que sua responsabilidade pessoal só será apurada mediante a verificação de culpa.

Uma vez reconhecida a relação consumerista entre médico e paciente, cumpre esclarecer se esta será contratual ou extracontratual. Pois bem, é amplamente aceito pelas doutrinas e jurisprudências brasileiras que a responsabilidade civil dos médicos está atrelada a existência de obrigações contraídas por contrato, seja este escrito ou verbal, de forma explícita ou tácita.

\footnotetext{
${ }^{31}$ CONFEDERAÇÃO NACIONAL DAS PROFISSÕES LIBERAIS. ESTATUTO SOCIAL. CNPL, 2019. Disponível em: 〈https://www.cnpl.org.br/wp-content/uploads/2020/o5/ESTATUTO-SOCIALCNPL.pdf $>$. Acesso em I2 abr. 2021.

32 BRASIL. LEI No 8.078, DE in DE SETEMBRO DE 1990. Código de Defesa do Consumidor. Disponível em: 〈http://www.planalto.gov.br/ccivil_03/leis/18o78compilado.htm〉. Acesso em 7 set. 2021.
} 
Por fim, cabe mencionar que estas relações contratuais culminam na existência de direitos e deveres para ambas as partes. E que, os danos resultantes do incumprimento ou do cumprimento defeituoso do que foi acordado entre médico-paciente, tornam possível e viável o requerimento de indenização por danos morais, materiais e lucros cessantes.

\title{
3.1.2 Na telemedicina, o médico possuirá obrigação de meio ou de resultado?
}

Outra questão, referente à natureza jurídica da relação médico-paciente, que costuma gerar controvérsia na doutrina diz respeito à distinção entre as obrigações de meio e de resultado, principalmente em relação a determinação de quem terá o ônus da prova para comprovação da responsabilidade.

Sobre esta questão, o doutrinador Flávio Tartuce esclarece que:

\begin{abstract}
De acordo com o entendimento majoritário, caso o profissional de saúde assuma umaobrigação de resultado, como no caso do médico cirurgião plástico estético, a sua responsabilidade é objetiva, ou seja, independe de culpa. No caso do médico cirurgião plástico reparador, bem como nos demais médicos e profissionais em geral, a obrigação é de meio ou de diligência e a premissa da sua responsabilização é a provada culpa (responsabilidade subjetiva). ${ }^{33}$
\end{abstract}

Com isto posto, pode-se definir que nas obrigações de meio, o profissional médico estará obrigado a empregar de forma diligente todos os seus conhecimentos e recursos a fim de fornecer o melhor tratamento possível aos pacientes sob seu cuidado. Contudo, vale ressaltar que nesta modalidade o profissional não estará assumindo uma obrigação de resultado, ou seja,o compromisso de curar o paciente.

Atualmente, encontra-se em vigor no Brasil a lei $n^{\circ}$ 13.989, de 15 de abril de 2020 , que dispõe a respeito do uso da telemedicina durante a crise causada pelo coronavírus (SARSCoV-2), e estabelece em seu artigo $5^{\circ}$ que "a prestação de serviço de telemedicina seguirá os padrõesnormativos e éticos usuais do atendimento presencial (...)"34.

Portanto, seria lógico afirmar que assim como no atendimento presencial a obrigação do profissional médico é, em regra, de meio. Desta forma, se for observado que o médico agiu com "os devidos cuidados, observando as normas técnicas, ou seja, sem

\footnotetext{
${ }^{33}$ TARTUCE, Flávio. Direito Civil: Direito das Obrigações e Responsabilidade Civil. 6. ed. São Paulo: Método,20II, p. 47. ${ }^{34}$ BRASIL. LEI № 13.989, DE is DE ABRIL DE 2020. Dispõe sobre o uso da telemedicina durante a crise causada pelo coronavírus (SARS-CoV-2). Disponível em:〈https://www.planalto.gov.br/ccivil_03/_ato2019-2022/2020/Lei/L13989.htm〉. Acesso em is set. 2021.
} 
negligência, imprudência ou imperícia, a responsabilidade de indenizar por não ter alcançado o resultado esperado é inexistente" ${ }^{35}$.

Ocorre que, ao analisar o artigo $14, \S 4^{\circ}$ do Código de Defesa do Consumidor (CDC), percebemos que ao introduzir no ordenamento jurídico brasileiro noções sobre a responsabilidade pessoal dos profissionais liberais, este, foi bastante contundente ao afirmar que "será apurada mediante a verificação de culpa".

A partir das informações acima mencionadas, conclui-se que a responsabilidade do médico no uso da telemedicina está inserida na teoria da responsabilidade civil subjetiva, pois a culpa só será caracterizada quando aquele que causou o dano não tiver tido a intenção de provocá-lo, mas, seja por imprudência, negligência, imperícia, acabou causando-o, gerando assim a obrigação de repará-lo.

\subsection{Pressupostos da responsabilidade civil médica no âmbito da telemedicina}

Para que haja a responsabilização do médico e, como consequência, sua obrigação de indenizar, é fundamental que se verifique a existência de um conjunto de pressupostos: a conduta do agente, o dano, o nexo de causalidade e a culpa.

Dentre os elementos caracterizadores da responsabilidade civil médica citados acima, perceberemos que os pressupostos de culpa e nexo de causalidade serão os mais difíceis de comprovar, uma vez que, são muitos os fatores (genética, sistema imunológico, cicatrização do paciente, se o paciente atende ou não as recomendações a risca...) que influenciam na cura ou tratamento realizados pelo médico.

O primeiro dos pressupostos que abordaremos é a conduta do agente, a qual pode ser exteriorizada por ação ou por omissão. Logo, para que possa se falar em erro médico e na responsabilização deste profissional, é necessário que se possa identificar e comprovar a realização de uma conduta ilícita, incorreta, em desacordo com o código de ética médica, que demonstre a imperícia, a imprudência, a negligência na condução do caso do paciente.

No entanto, não basta, para que seja configurada a responsabilidade civil, a prática

\footnotetext{
${ }^{35}$ BONHO, Luciana. Tramontin; CARVALHO, Francisco Toniolo de; ARAUJO, Marjorie de Almeida; BONFADA, Elton; OlIVEIRA, Amanda Muniz; DUARTE, Melissa de Freitas; FRAGA, Patrícia Fernandes; PIETRO, Renata Barros; GALASCHI, Bruna; FREITAS, Edmundo Gouvêa; LEAL, Fabiana Hundertmarck; ARAKAKI, Fernanda Franklin Seixas; PORTELLA, Mariana. Responsabilidade civil. Porto Alegre: Sagah, 202o. Disponível em: 〈https://integrada.minhabiblioteca.com.br/\#/books/9788595024199/>. Acesso em 29 set. 2021.
} 
de uma conduta equivocada pelo médico, é necessária a ocorrência de um dano a um bem juridicamente protegido, tal como a saúde e integridade física do paciente.

A respeito disso, Rui Stoco preleciona que:

O dano é, pois, elemento essencial e indispensável à responsabilização do agente, seja essa obrigação originada de ato ilícito ou de inadimplemento contratual, independente, ainda, de se tratar de responsabilidade objetiva ou subjetiva. ${ }^{36}$

A fim de ilustrar esta situação, o artigo "Erro médico: pressupostos da responsabilidade civil do profissional de saúde" ${ }^{37}$ trouxe à tona uma situação em que um paciente, ao apresentar manchas na pele, procurou um dermatologista que o diagnosticou erroneamente com

Vitiligo. E posteriormente, após consultar um colega a respeito a respeito do quadro de seu paciente, chegou ao diagnóstico correto de lupos, a partir do qual iniciou, logo em seguida, o tratamento adequado e as manchas na pele desapareceram sem qualquer sequela. No caso em comento, é percetível que apesar de ter havido um erro inicial de diagnóstico, não houve quaisquer danos concretos a saúde deste paciente e, portanto, não há que se falar em reparaçãocivil.

Vale ressaltar ainda que no passo em que a telemedicina se encontra, o médico precisa redobrar os cuidados, uma vez que, inexiste a possibilidade de realização de um exame físico ao longo da consulta, aumentando assim a possibilidade e os riscos no fornecimento de diagnósticos. Em razão disto, o artigo $4^{\circ}$ da Lei 13.989/2020 julgou importante mencionarque "O médico deverá informar ao paciente todas as limitações inerentes ao uso da telemedicina, tendo em vista a impossibilidade de realização de exame físico durante aconsulta" ${ }^{38}$.

Por sua vez, o terceiro pressuposto a ser analisado a fim de caracterizar, ou não, o deverde indenizar é o "nexo de causalidade" entre o a conduta do agente e o dano causado. Sobre este assunto discorre Silvio de Salvo Venosa:

\footnotetext{
${ }^{36}$ STOCO, Rui. Tratado de responsabilidade civil: doutrina e jurisprudência. 7. ed. São Paulo: Revista dosTribunais, 2007, p. 73.

${ }^{37}$ IABD INSTITUTO ANA BROCANELO DE DIREITO. Erro médico: pressupostos da ResponsabilidadeCivil do profissional de saúde. Direito Médico. Jus Brasil, 2019. Disponível em: <https://iabd.jusbrasil.com.br/artigos/70206958I/erro-medico-pressupostos-da-responsabilidade-civil-doprofissional-de-saude $>$. Acesso em io nov. 2020.

${ }^{38}$ BRASIL. LEI № 13.989 , DE Is DE ABRIL DE 2020. Dispõe sobre o uso da telemedicina durante a crise causada pelo coronavírus (SARS-CoV-2). Disponível em: 〈https://www.planalto.gov.br/ccivil_03/_ato20192022/2020/Lei/Li3989.htm>. Acesso em is set. 2021.
} 
[...] é o liame que une a conduta do agente ao dano. É por meio do exame da relaçãocausal que concluímos quem foi o causador do dano. Trata-se de elemento indispensável. Se a vítima, que experimentou um dano, não identificar o nexo causal que leva o ato danoso ao responsável, não há como ser ressarcida. ${ }^{39}$

Ou seja, mesmo que seja verificada a realização de uma conduta culposa por parte domédico, esta só culminará no dever de indenizar se houver relação entre ela e o dano causado.E, por fim, o último elemento caracterizador da responsabilidade civil a ser mencionado é a culpa. Diferentemente do dolo onde há a intenção e o planejamento do danoa ser provocado, na culpa o resultado não é pretendido por seu causador, embora este seja previsível.

Sendo assim, pode-se definir culpa como "[...] a inobservância de um dever que o agente deveria conhecer e observar ${ }^{40}$ ", logo tem-se que se o agente deixar de lado a diligêncianecessária para a realização de uma determinada conduta, seja em razão da falta de atenção, cuidado ou cautela, este deverá responder pelo resultado gerado. Assim, de acordo com

Luciana Tramontin Bonho et $\mathrm{al}^{4 \mathrm{I}}$, a culpa se manifestará por meio de três formas distintas: a imprudência "caracterizada pela prática de ato perigoso"; a negligência "fundada na ausência de precaução que leva o agente a deixar de fazer algo imposto pela norma jurídica"; e/ou a Imperícia "concretizada na falta de aptidão para o exercício de arte ou profissão”.

\section{EVOLUÇÃO E PERSPECTIVAS}

Neste tópico, discorreremos tanto a respeito dos possíveis benefícios advindos da utilização da telemedicina quanto sobre os obstáculos a serem enfrentados até que a esta seja considerada uma prática comum e acessível a todos os brasileiros. Vale ressaltar ainda que as informações trazidas nos subtópicos a seguir foram embasadas em suposições e experiências vivenciadas em países estrangeiros.

\footnotetext{
${ }^{39}$ VENOSA, Silvio de Salvo. Direito Civil: Responsabilidade Civil. 5. ed. São Paulo: Atlas, 2011, p. 53.

${ }^{40}$ Idem.

${ }^{41}$ BONHO, Luciana. Tramontin; et al., op. cit., p. I.
} 


\subsection{Benefícios trazidos pela implementação da telemedicina no Brasil}

O impacto da telemedicina em diversos países ao redor do mundo constatou que é possível atestar muitos benefícios assistenciais, sociais e econômicos no sistema de saúde. As vantagens trazidas pela tecnologia são várias, desde a redução dos custos com deslocamento à ampliação do acesso à assistência médica.

Apesar do Conselho Federal de Medicina ter permitido a prática de telemedicina no Brasil somente durante a pandemia, já é um grande avanço para a questão da implementação definitiva e regulamentação do método. Para que o serviço de telemedicina funcione, é necessária uma plataforma de telecomunicação que permita o envio ou troca de informação entre as pessoas que estão em locais geográficos distantes. Desse modo, com o uso da internet é possível acessá-la de qualquer lugar do planeta e realizar o atendimento remoto.

Esse é um dos maiores benefícios que o recurso pode trazer ao serviço de saúde, principalmente em países como o Brasil, onde há concentração de especialistas em determinados estados ou cidades mais populosas. Os pacientes de áreas com menor assistência, como o interior dos estados, podem receber amparo de especialistas de outros locais, sem precisar se deslocar até um centro urbano para concluir o atendimento, quemuitas vezes não é realizado devido aos altos valores que envolvem o deslocamento.

o profissional, por sua vez, consegue aumentar a sua capacidade de atendimento. Será possível atender pacientes de outras localidades, não ficando restrito somente ao consultório. Com a facilidade de busca de informações pela internet, é possível que o paciente encontre um profissional de sua preferência em qualquer lugar do país. Considerando também que as trocas de informações entre médicos especialistas facilitam uma interação em tempo real. Além disso, toda a informação do paciente fica armazenada em prontuário eletrônico. Isso simplifica o acesso entre vários profissionais de saúde de uma mesma equipe médica, otimizando o tempo de espera nas filas de consultórios e hospitais.

Em suma, a vantagem disso é a agilidade nos trâmites das informações, acesso e qualidade da assistência, produtividade dos serviços, organização da rede de atenção, redução de custos para o sistema e aos seus usuários otimizando o trabalho 
multidisciplinar, além de um diagnóstico mais preciso, o que torna os benefícios da telemedicinaextremamente imprescindíveis ao mundo globalizado.

- Praticidade: grande parte das idas a um consultório médico é para realizar consultasou exames que podem ser feitos tranquilamente através da câmera. Nesse sentido, fica muito mais viável e prático realizar os procedimentos sem precisar se locomover para um hospital ou consultório médico.

- Redução de custos: pelo fato de a maioria dos hospitais estarem localizados somenteem grandes centros, grande parte da população, quando vai a um hospital acaba tendo que arcar com vários custos extras, como transporte, alimentação e quando necessário, hospedagem. Assim como as clínicas também podem evitar custos com a manutenção da infraestrutura do consultório.

- Acesso a resultados via internet: Os dados do paciente e os resultados de seus exames ficam disponíveis na web, protegidos para que apenas os profissionais e o paciente possam visualizá-los.

- Acesso a segunda opinião: com a teleinterconsulta, médicos podem trocar informações e opiniões sobre determinada situação de algum paciente. Tornando laudos,exames e tratamentos mais precisos e eficientes.

Diante de todas essas informações deve-se ponderar e considerar que a telemedicina não age contra a medicina tradicional e sim como um braço para a metodologia convencional, representando um grande avanço tecnológico, proporcionando uma melhora da qualidade da assistência e, com isso, melhora dos resultados de saúde.

\section{2 desvantagens e obstáculos para a implementação da telemedicina}

Apesar dos claros benefícios que a telemedicina pode vir a proporcionar, existem aindaalguns obstáculos a serem superados. Por ser um assunto relativamente novo, muitos profissionais médicos ainda não detêm o conhecimento adequado e não conseguem entender seus benefícios. Além disto, o elevado custo dos equipamentos de videoconferência e a inexistência de conexões de alta velocidade em regiões remotas são um outro obstáculo adicional a ampliação do serviço.

Outra barreira para o desenvolvimento da telemedicina no Brasil, é a falta de uma 
política adequada para a renumeração dos profissionais pelos serviços prestados. As tabelas dehonorários dos planos de saúde, seguradoras, cooperativas médicas e governo ainda não contemplam tais procedimentos. Sem isto, o serviço de telemedicina ficará restrito a pacientesparticulares.

Apesar da resolução do Conselho Federal de Medicina de 2002, que fixou algumas normas de conduta para a telemedicina, ainda existe um vácuo legal, quanto a uma melhor regulamentação ética e uma legislação específica sobre o assunto. A insegurança jurídica decorrente disto restringe a ampliação dos serviços. Temas como a prática profissional, consentimento bem-informado, privacidade, proteção de dados e confidencialidade precisam ser melhor delimitados para o exercício seguro da atividade profissional. Alguns aspectos importantes ainda precisam ser melhor definidos, como a necessidade do profissional possuir licença profissional (CRM) em cada estado que o paciente estiver acessando os serviços, a proibição de realizar consultas tele médicas diretamente entre o paciente e o profissional, a telemedicina transfronteiras, dentre outros assuntos.

Mas não é apenas no Brasil que a telemedicina encontra dificuldades para ampliar sua aplicação. Scott Kruse et al., ${ }^{42}$ realizou uma revisão sistemática listando os principais desafios e obstáculos para o crescimento da telemedicina em todo o planeta. Suas descobertas também

apontaram os mesmos problemas do Brasil, como dificuldades técnicas, resistências a mudanças, custos envolvidos, nível educacional dos pacientes e a regulamentação local.

Destes pontos levantados, a regulamentação é, de longe, o principal ponto de discussão e uma das causas dos diferentes níveis da aplicação da telemedicina entre os países. Pontos críticos de "como implementar", "quando pode ser utilizada", "quem pode fazer uso" e "sob quais circunstâncias" a telemedicina pode ser aplicada ainda geram muita discussão e polêmica, principalmente no que se refere a teleconsultas e ao contato médicopaciente sem a mediaçãode uma instituição ou de outro profissional de saúde.

\footnotetext{
${ }^{42}$ SCOTT KRUSE, C., KAREM, P., SHIFFLETT, K., VEGI, L., RAVI, K., \& BROOKS, M. (2or8). Evaluating barriers to adopting telemedicine worldwide: A systematic review. Journal of telemedicine and telecare, 24(I), 4-I2. In: SANTOS, Weverson Soares; SOUZA JÚNIOR, João Henrique; SOARES, João Coelho; RAACH, Michele. REFLEXÕES ACERCA DO USO DA TELEMEDICINA NO BRASIL: OPORTUNIDADE OU AMEAÇA?. Revista de Gestão em Sistemas de Saúde - RGSS, Health Systems Management Journal - HSMJ, 23. Jun. 2020, e-ISSN: 2316-3712. Disponível 〈https://periodicos.uninove.br/revistargss/article/view/17514〉. Acesso em Ioabr. 2021.
} 
O maior temor das associações médicas é que a popularização da telemedicina uma vez sendo adotada em massivamente, transforme o profissional médico em um mero “atendente detelemarketing", reduzindo a demanda por médicos, causando desemprego no setor e incrementando os erros de diagnósticos.

No Brasil, a resolução CFM 2.227/18 foi duramente criticada, principalmente por questões relacionadas com a qualidade do atendimento, aumento da possibilidade de diagnósticos equivocados, insegurança quanto ao sigilo e guarda das informações geradas nos atendimentos de telemedicina. As entidades médicas também alertaram que, o uso exacerbadodesta tecnologia poderia ser causa de desemprego de profissionais médicos ${ }^{43}$. A revogação desta resolução mostrou que não há um consenso em relação ao tema.

Portugal é um pais onde a telemedicina apresentou grande desenvolvimento. Abreu, 2014, e Santos, 2015 estudaram a experiência dos portugueses com a telemedicina. Segundo eles, a percepção do grupo estudado, de forma sintética, a maior preocupação é quanto a segurança das informações e privacidade dos usuários. Tais fatores podem influenciar apopulação na decisão de utilizar ou não o serviço.

Nos EUA, segundo Spear et $a 1 .{ }^{44}$, levantaram que a maior desvantagem apresentada pelos entrevistados estudados, é a quanto a impossibilidade de se fazer um exame físico com atelemedicina. Outro fator levantado foi a falta de relacionamento e intimidade entre paciente e médico, o que em muitos casos dificulta o correto diagnóstico. Problemas técnicos durante o atendimento também foram repostados neste estudo. Ainda segundo este estudo, apenas $25 \%$ dos entrevistados reportou preferir o atendimento virtual.

\section{CONSIDERAÇÕES FINAIS}

As informações apresentadas ao longo do presente trabalho demonstraram a existência de um processo natural que levou os profissionais da saúde a empregarem os recursostecnológicos a sua disposição para a prática da medicina. Desta forma, buscou-se demonstrar os diferentes níveis de aceitação da prática da telemedicina em países distintos,

\footnotetext{
${ }^{43}$ SANTOS, Weverson Soares; SOUZA JÚNIOR, João Henrique; SOARES, João Coelho; RAACH, Michele. op.cit., p.

${ }^{44}$ SPEAR, K. L., AUINGER, P., SIMONE, R., DORSEY, E., \& FRANCIS, J. Patient Views on Telemedicine for Parkinson Disease. Journal of Parkinson's Disease, 9(2), 401-404. In: SANTOS, Weverson Soares; SOUZA JÚNIOR, João Henrique; SOARES, João Coelho; RAACH, Michele. op. cit., p. I.
} 
bem como quaissão as modalidades já empregadas.

Dentre os principais benefícios trazidos pelo uso da telemedicina no Brasil, foram destacados: a redução de custos com o deslocamento; a transposição de barreiras geográficas a fim de fornecer atendimento especializado a população que vive em regiões com uma escassezde profissionais; a praticidade e comodidade em poder ser atendido sem sair de casa; a possibilidade de médicos trocarem informações e opiniões sobre determinado paciente a partir de locais distintos em tempo real (teleinterconsulta) e etc. Além disso, nota-se também que a telemedicina tem sido utilizada como forma muito benéfica e eficaz de acompanhar pacientes com doenças crônicas em seu próprio domicilio (telemonitoramento).

Já dentre as preocupações e desvantagens advindos da utilização e regulamentação da telemedicina demonstradas ao longo do artigo, é necessário enfatizar o temor das associações médicas de que a demanda por médios seja reduzida, gerando uma onda de desemprego no setor e um aumento no número de diagnósticos equivocados, uma vez que a telemedicina impossibilita a realização de exames físicos. Além disso, é importante ressaltar que no Brasil, existe uma imensa desigualdade na distribuição/acesso à equipamentos de videoconferência e conexões de alta velocidade, impossibilitando assim que uma parcela considerável da população utilize o recurso.

Outra preocupação proeminente no Brasil diz respeito a insegurança jurídica trazida pela falta de uma legislação atualizada específica sobre o tema. Visto que, antes da pandemia do novo coronavírus estava em vigor no país a Resolução do CFM I.643/o2, publicada no dia 26 de agosto de 2002, anos antes do surgimento dos dispositivos e aplicativos atualmente utilizados para a prática da telemedicina. Em razão deste cenário e das restrições estabelecidas pela resolução vigente, muitos dos possíveis investidores tem apresentado ressalvas em investir no desenvolvimento e segurança de plataformas específicas para esta atividade.

Contudo, apesar deste cenário e das dificuldades demonstradas para a implementação da telemedicina no Brasil, pode-se dizer que a experiência trazida pela Lei n. ${ }^{\circ} 13.989 / 20$ ao longo da pandemia do novo coronavírus oportunizou que médicos e pacientes experienciassem 
ateleconsulta em primeira mão. E, como consequência, as partes interessadas: governo, sociedade, profissionais e operadoras de saúde passaram a aprofundar as discussões acerca da possibilidade e eticidade de se desenvolver uma regulamentação mais ampla a respeito da telemedicina.

\section{EFERENNCIAS}

ASSOCIAÇÃO BRASILEIRA DE MANTENEDORIAS DE ENSINO SUPERIOR.

RESOLUÇÃO № 2.228, DE 26 DE FEVEREIRO DE 2019. ABMES, 2019. Disponível em: 〈https://abmes.org.br/arquivos /Resolucao-CFM-2228-2018-02-26.pdf $>$.Acesso em I2 abr. 2021.

ATA NEWS. Schatz, Wicker Lead Bipartisan Group Of so Senators In Reintroducing Legislation To Expand Telehealth Access, Make Permanent Telehealth Flexibilities Available During COVID-rg Pandemic. American Tele Med, 2021. Disponível em: <https://www.americantelemed.org/policy/schatz-wicker-lead-bipartisan-group-of-5osenators-in-reintroducing-legislation-to-expand-telehealth-access-make-permanent-telehealthflexibilities-available-during-covid-19-pandemic/>. Acesso em I2 abr. 202I.

BERTOLINI, Gina L. Connect for Health Act of 202I Reintroduced. 2021. Disponível em: 〈https://www.natlawreview.com/article/connect-health-act-2021-reintroduced〉. Acesso emI2. Abr. 2021.

BENNER. Telemedicina: O que é, como funciona e quais são os benefícios. Benner, Saúde, 202I. Disponível em: 〈https://www.benner.com.br/telemedicina-o-que-e/>. Acessoem I2 abr. 2021.

BONHO, Luciana. Tramontin; CARVALHO, Francisco Toniolo de; ARAUJO, Marjorie de Almeida; BONFADA, Elton; OlIVEIRA, Amanda Muniz; DUARTE, Melissa de Freitas; FRAGA, Patrícia Fernandes; PIETRO, Renata Barros; GALASCHI, Bruna; FREITAS, Edmundo Gouvêa; LEAL, Fabiana Hundertmarck; ARAKAKI, Fernanda Franklin Seixas; PORTELLA, Mariana. Responsabilidade civil. Porto Alegre: Sagah, 2020. Disponível em: 〈https://integrada.minhabiblioteca.com.br/\#/>. Acesso em 29 set.2021.

BRASIL. PORTARIA № 467, DE 20 DE MARÇO DE 2020. Disponível em: 〈http://www.planalto.gov.br /Portaria/PRT/Portaria\%2on\%C2\%BA\%20467-20- ms.htm>. Acesso em 29 set. 2021.

Portaria n.o 567/2006. Diário da República Eletrônico, Ministério da Saúde, p. 4173-4267, 2006. Disponível em:〈https:/ pesquisa/search/346716/s/maximized〉. Acesso em 29 set. 2021.

. LEI № 8.078, DE II DE SETEMBRO DE 1990. Código de Defesa do Consumidor. Disponível em: 〈http://www.planalto.gov.br/ /leis/18o78compilado.htm〉. 
Acesso em 7 set. 202I.

LEI № 10.406, DE ro DE JANEIRO DE 2002. Código Civil. Disponível em:〈http://www.planalto.gov.br/ccivil_03/leis/lio406.htm>. Acesso em I5 set. 202I.

LEI № 13.989, DE is DE ABRIL DE 2020. Dispõe sobre o uso da telemedicina durante a crise causada pelo coronavírus (SARS-CoV-2). Disponível em: 〈https://www.planalto.gov.br/ccivil_03/_ato2019-2022/2020/Lei/Li3989.htm〉. Acesso emis set. 202I.

CANCIAN, Natália; COLLUCCI, Cláudia. Apesar de críticas, telemedicina já é realidade no país e deve se expandir. ABRAMGE, 2019, fonte Folha de S. Paulo. Disponível em:<https://www.abramge.com.br/portal/index.php/pt-BR/ 985-apesar-de- -ja-erealidade-no-pais-e-deve-se-expandir $>$. Acesso em is abr. 2021.

CAVAliERI FILHO, Sérgio. Programa de Responsabilidade Civil. II. ed. São Paulo: Atlas, 2014.

CONDE, Luiz Felipe; CARVALHO, Abner Brandão. A responsabilidade civil do médico no uso da telemedicina. Consultor Jurídico, 2020. Disponível em: <https://www.conjur.com.br/2020-set-or/responsabilidade-civil-medico-usotelemedicina\#_ftnrefi $>$. Acesso em I6 abr. 2021.

CONFEDERAÇÃO NACIONAL DAS PROFISSÕES LIBERAIS. ESTATUTO SOCIAL.

CNPL, 2019. Disponível em: <https://www.cnpl.org.br/wpcontent/uploads/2020/o5/ESTATUTO-SOCIAL-CNPL.pdf >. Acesso em I2 abr. 202I.

CONSELHO FEDERAL DE MEDICINA. Conselheiros do CFM revogam a Resolução no 2.227/2018, que trata da Telemedicina. Portal CFM, 2019. Disponível em: $<$ https://portal.cfm.org.br/?option=com_content\&id=28096\%3A2019-02-22-15-13-20 . Acesso em 26 out. 2020 .

. OFÍ́CIO CFM № 1756/2020 - COJUR. Brasília, 2020. Disponível em: $\mathrm{http}: / /$ portal.cfm.org.br/images/PDF/2020_oficio_telemedicina.pdf $>$. Acesso em is maI. 2021.

CONSELHO REGIONAL DE MEDICINA DO ESTADO DE SÃO PAULO. Resolução CFM no 1.643, de 7 de Agosto de 2002. Conselho Federal de Medicina, Diário Oficial da União, Poder Executivo, Brasília, DF, 2002. Disponível em: $<$ https://www.cremesp.org.br/?siteAcao=PesquisaLegislacao\& $\mathrm{dif}=\mathrm{s} \&$ ficha $=\mathrm{I} \& \mathrm{id}=3$ Io6\&tipo $=\mathrm{RESOLU} \% \mathrm{C}_{7} \% \mathrm{C}_{3} \mathrm{O} \&$ orgao $=$ Conselho\%2oFederal\%2ode\%2oMedicina\&nu mero $=1643 \&$ si tuacao $=$ VIGENTE \&data $=0$ 7-08-2002 $>$. Acesso I5 mai. 2021 .

DAVIS, Jessica. CONNECT for Health Act unveiled; Expands use of telemedicine, 
saves $\$$ I.8 bilion. Healthcare It News, 2016. Disponível em:<https://www.healthcareitnews.com/news/connect-health-act-unveiled-expandsuse- telemedicine-saves-I8-billion>. Acesso em I2 abr. 202I.

DHNET. Declaração de Telavive sobre responsabilidades e normas éticas na

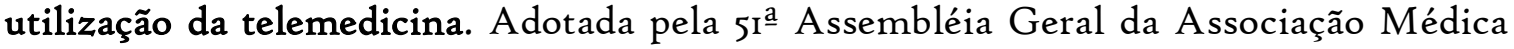
Mundial em Tel Aviv, em outubro de 1999. Disponível em: 〈http://www.dhnet.org.br/ codetica/medica/27telaviv.html>. Acesso em 20 abr. 2021.

DIÁRIOS DA REPÚBLICA. Despacho 3571/2013, de 6 de Março. Ministério da Sáude Gabinete do Secretário de Estado Adjunto do Ministério da Saúde, o6-03-2013. Disponível em: 〈https://dre.tretas.org/dre/30746I/despacho-3571-2013-de-6-de-marco〉. Acesso em 07mar. 2021.

\section{DUARTE, Andreia Filipa Santos. TELEMEDICINA: OS NOVOS DESAFIOS À}

RESPONSABILIDADE CIVIL MÉDICA: a emergência de uma nova forma de prestar consentimento. Dissertação (Mestrado) - Curso de Direito, 6of, Universidade do Porto, Porto,2018. Disponível em: <https://repositorio- aberto.up.pt/bitstream/10216/117905/2/ >. Acesso em I2 abr. 2021.

FALEIROS JUNIOR, José Luiz de Moura; NOGAROLI, Rafaella; CAVET, Caroline Amadori. Telemedicina e Proteção de Dados: Reflexões sobre a pandemia da Covid-ı9 e os impactos jurídicos da tecnologia aplicada à saúde. São Paulo: Revista dos Tribunais, 2020 .

FREITAS, Lucimer Coelho de. A implementação da telemedicina no Brasil e seu caráter social. Migalhas, 2020. Disponível em: 〈https://www.migalhas.com.br/depeso/324157/aimplementacao-da-telemedicina-no-brasil-e-seu-carater-social >. Acesso em I2 abr. 202I.

GLOBO. A nova realidade da telemedicina. Infografico, Gente, Rio de Janeiro, in set. de 2020. Disponível em: 〈https://gente.globo.com/a-nova-realidade-da-telemedicina/〉. Acessoem 25 abr. 2021.

IABD INSTITUTO ANA BROCANELO DE DIREITO. Erro médico: pressupostos da Responsabilidade Civil do profissional de saúde. Direito Médico. Jus Brasil, 2019. Disponível em: <https://iabd.jusbrasil.com.br/artigos/70206958I/erro-medico-pressupostos- daresponsabilidade-civil-do-profissional-de-saude>. Acesso em io nov. 2020.

LEGIFRANCE. Article L6316-i. Modifilé par LOI no 2017-1836 du 30 décembre 2017 - art. $54 \quad(V)$. Disponível em: 〈https://www.telemedecine-36o.com/wpcontent/uploads/2019/or/D\%C3\% \% $\%$ 3\% A9m\%C3\%A9decine.pdf $>$.Acesso em 12 abr. 2021.

MARTINS, Guilherme Magalhães; TELES, Carlos André Coutinho. A TELEMEDICINANA SAÚDE SUPLEMENTAR E A RESPONSABILIDADE CIVIL DO MÉDICO NO TRATAMENTO DE DADOS À LUZ DA LGPD. Tese (Doutorado) - Curso de Direito, I6f, Universidade Federal do Rio de Janeiro - Brasil, Rio 
de Janeiro, 202I. Disponível em: 〈https://www.estudosinstitucionais.com/REI/art>. Acesso em 25 abr. 2021.

MORSCH, José Aldair. COMO FUNCIONA A TELESSAÚDE NO BRASIL, SUA LEGISLAÇÃO E BENEFÍCIOS. Telemedicina Morsch, 2020. Disponível em: <https://telemedicinamorsch.com.br/blog/ -brasil >. Acesso em io abr. 202I.

ROUZIC, Mathilde le. Remboursement des teléconsultations. Hellocare, blog, 202I. Disponível em: 〈https://blog.hellocare.pro/remboursement-des-teleconsultations〉. Acesso emi2 abr. 2021.

SABBATINI, Renato M. E. A Telemedicina no Brasil: Evolução e Perspectivas. São Bernardo do Campo: Yendis, I912. Disponível em: <https://www.sabbatini.com/renato/ Telemedicina_Brasil_Evolucao_Perspectivas.pdf $>$. Acesso em io abr. 202I.

SANTOS, Weverson Soares; SOUZA JÚNIOR, João Henrique; SOARES, João Coelho; RAACH, Michele. REFLEXÕES ACERCA DO USO DA TELEMEDICINA NO BRASIL: OPORTUNIDADE OU AMEAÇA?. Revista de Gestão em Sistemas de Saúde - RGSS

health Systems Management Journal - HSMJ, 23. Jun. 2020, e-ISSN: 2316-3712. Disponívelem: $\langle$ https://periodicos.uninove.br/revistargss/article/view/175I4〉. Acesso em Io abr. 202I.

SAÚDE BUSINESS. O cenário europeu da telessaúde. AGRJ, Socgastro, 2020. Disponível em: <https://socgastro.org.br/novo/2020/o7/o-cenario-europeu-datelessaude/>. Acesso em I2abr. 2021.

SCHATZ SENATE. CONNECT for Health Act of 202I. Senators Schatz, 202I. Disponívelem:<https://www.schatz.senate.gov/imo/media/doc/CONNECT\%2ofor\%2oHealth \%20Act\%200f\%202021_Summary_6.15.2021.pdf>. Acesso em I2 abr. 2021.

SHAH, Bimal. The Pandemic Changed Telehealth; Next, Telehealth May Change Healthcare. Amererican Telemed, 202I. Disponível em: $<$ https://www.americantelemed.org/ / >. Acesso em I2 abr. 2021.

STEINBRENNER, Luiz Gustavo; KUHN, Monica Jappe Goller; KUHN, Kleberson. A RESPONSABILIDADE CIVIL DO MÉDICO COMO PROFISSIONAL LIBERAL. Jus, 2016. Disponível em: 〈https://jus.com.br/artigos/45617/a-responsabilidade-civil-do-medicocomo-profissional-liberal/2>. Acesso em I2 abr. 2021.

STOCO, Rui. Tratado de responsabilidade civil: doutrina e jurisprudência. 7. ed. São Paulo: Revista dos Tribunais, 2007.

TARTUCE, Flávio. Direito Civil: Direito das Obrigações e Responsabilidade Civil. 6. ed. São Paulo: Método, 20Ir. 
VENOSA, Silvio de Salvo. Direito Civil: Responsabilidade Civil. 5. ed. São Paulo: Atlas, 2011.

VIANA, Fernanda Martins. Telemedicina: uma ferramenta para ampliar o acesso à assistência em saúde no Brasil. FGV EARSP, 2015. Disponível em: <https://eaesp.fgv.br/producao-intelectual/telemedicina-ferramenta-para-ampliar-acessoassistencia-saude-brasil>. Acesso em 12 abr. 2021. 